Available online at http://jgu.garmian.edu.krd

Journal of Uni versity of Garmian

https://doi.org/10.24271/garmian.196354

\title{
Difficulties and Problems of Simultaneous Interpretation in Kurdistan Region - Iraq
}

\author{
Ako Subhi Ghaza'ee , Wrya Izzadin Ali \\ English Department - College of Languages- Salahaddin University-Erbil
}

\section{Article Info}

Received: July, 2019

Revised:July,2019

Accepted:August,2019

\section{Keywords}

Translation, Interpretation, Simultaneous Interpretation

Corresponding Author

qa_kirkuk@yahoo.com

\begin{abstract}
Translation is one of the most important branches of linguistics, conveying and rendering message from one language to another is not something easy, but written translation is considered easier than oral translation, since the first has enough time and opportunity to convey the meaning from one language to another, while the later has not. This paper tries to study one of the important sides of simultaneous interpretation (henceforth SI), it is difficulties and problems of SI. The aims of the study are identifying literature review of SI like; the concept of SI, history, types, qualifications, and difficulties and problems that face the process of SI, then finding out suitable solutions for such difficulties. Methodologically, this study is based on the interview aspect as to collect data and knowledge about the topic of the study, and designing questionnaire. These two tools are submitted to simultaneous interpreters, i.e., study sample in Kurdistan Region, Erbil, Sulaymaniyah, Dohuk, and Kirkuk governorates-Iraq. After distributing the two tools and analyzing the collected data, the study concludes that there are serious difficulties and problems facing simultaneous interpretation. The following quantitative results are obtained after using (SPSS), $(\mathrm{M}=4.01)$ with $(\mathrm{SD}=0.78)$.
\end{abstract}

\section{Introduction}

Interpretation, oral translation, is a crucial task, since it deals with the intended meaning of the speaker. The interpreter's job differs completely from the translators. The first deals with communicating the message from one language to another, while the later deals with changing the text from language to another. Very few researches had been studied before about SI in Iraq, especially in Kurdistan Region. Thus, it is very necessary to study such topics. Evaluating the process of SI, specifically the difficulties and problems of SI in Kurdistan Region-Iraq is important. Thus, the current study comes to shed light on SI, difficulties, problems, and the solutions for those difficulties and problems. 


\section{Literature Review}

\section{The Concept of Interpre tation}

Interpretation is described by its immediacy. Interpreters give a first and last delivering of expressed message in real time and for at once communicative use. The message of the source language (henceforth SL), as well as the target language (henceforth TL) are typically a normal language, in the oral or signed modality, fundamentally ephemeral requiring immediate processing1. Language interpretation is the facilitating of oral or sign language communication, either simultaneously or consecutively, between users of different languages. The process is described by both the words 'interpreting' and 'interpretation'. In professional parlance, interpreting denotes the facilitating of communication from one language form into its equivalent, or approximate equivalent, in another language form; while interpretation denotes the actual product of this work, that is, the message thus rendered into speech, sign language, writing, non-manual signals, or other language forms. 2

This important distinction is observed in order to avoid confusion. Accordingly, an interpreter is a person who converts a thought or expression in a SL into an expression with a comparable meaning in a TL in 'real time'. The interpreter's function is to convey every semantic element (tone and register) and every intention and feeling of the message that the SL speaker is directing to TL recipients. Despite being used incorrectly as interchangeable, 'interpretation and 'translation' are not synonymous. Interpreting takes a message from a SL and renders that message into a different $T L$, for example English into French. In interpreting, the interpreter will take in a complex concept from one language, choose the most appropriate vocabulary in the TL to faithfully render the message in a linguistically, emotionally, tonally, and culturally equivalent message.

\subsection{Historical Perspective of Interpretation}

The need for interpretation at international conferences is developed during the First World War. Before that time, French was the only formal diplomatic language. At the Congress of Vienna in 1814-1815, for instance, the participants were either diplomats with a perfect knowledge of French, or high ranking officers who had been elected expressly because they spoke French. This was also the case at the meetings of the World Postal Union (henceforth WPU). Further, communication between that institution which speak different languages was carried out mainly through dispatches and notes, which only needed written translations.

Interpreting today is taken for granted at international conferences. There are permanent booth installations in every main conference hall around the world. It is, however, a considerable new profession, whose origins date back to less than a century ago. Interpreting was born around 1920, after languages other than French were recognised as official diplomatic languages. Consecutive and whispering interpreting were the first techniques used, interpreting at the League of Nations in Geneva before the Second World War was similar to simultaneous interpreting, but simultaneous interpreting was invented later. The need for interpretation became more acute with the foundation of the League of Nations and the meetings of the International Labor Organisation. Moreover, it sometimes happened that groups of delegates, such as trade unionists, would speak neither English nor French. They were supplied with interpreters who whispered them the translation of the proceedings in their languages and interpreted their speeches consecutively. 3

The first usage of SI was at a conference of the International Labor Organisation in Russia in 1927. The public was introduced to SI as a communication tool at the Nuremburg war crime trials beginning in 1945. The United Nations is perhaps the best-known institution, which 
regularly relies on this form of interpretation to allow its members to communicate in any of the six official languages. Because of advances in technology and the development of special training programs for interpreters over the last thirty years, SI is now available at a reasonable cost for international events, conferences and meetings of all kinds and sizes.42.3 Types of Interpretation

There are five types of interpretation. They are clarified as follow:

\subsubsection{Simultaneous Interpretation}

SI is a unique skill that requires far more than the ability to speak multiple languages. Simultaneous interpreters have years of highly specialised education and training, the rare talent of being able to listen to one language while speaking another, and knowledge of terminology in tremendously varying fields. The professional circle of conference-level interpreters is extremely small. There are only 3000-4000 interpreters in the world for all languages and many are employed by international organisations. Many freelance interpreters are booked for events around the world months in advance. SI is a process which allows people to communicate directly across language and cultural boundaries, using specialized technology and professional interpreters who are trained to listen to one language while speaking simultaneously in another. SI differs from other types of interpretation, and from translation, which refers to the written word.5

\subsubsection{Consecutive Interpretation}

In consecutive interpretation (henceforth $\mathrm{CI}$ ), the interpreter speaks after the SL speaker finishes speaking. The speech is divided into segments, and the interpreter sits or stands beside the SL speaker, listening and taking notes as the speaker progresses through the message. When the speaker pauses or finishes speaking, the interpreter then renders a portion of the message or the entire message in the TL.6 CI is rendered as the interpreter relies on memory.

\subsubsection{Whispered Interpretation}

In whispered interpretation, the interpreter sits or stands next to the small TL audience whilst whispering SI of the matter to hand. This method requires no equipment, but may be conducted via a microphone and headphones if the participants prefer. Chuchotage is used in circumstances where the majority of a group of speakers the SL, and a minority ideally no more than three people, do not speak it.7

\subsubsection{Relay Interpretation}

Relay interpretation is usually used when there are several TLs. An SL interpreter interprets the text to a language common to every interpreter, who then renders the message to its respective TLs. For example, a Japanese source message first is rendered to English to a group of interpreters, who listen to English and render the message into Arabic, French, Russian, and other TLs. In heavily multilingual meetings, there may be more than one "intermediate" language, i.e. a Greek SL could be interpreted into English and then from English to other languages at the same time, it may also be directly interpreted into French, and from French into more languages. This solution is most often used in the multilingual meetings of the EU institutions.8

\subsubsection{Liais on Interpretation}

Liaison interpretation involves relaying what is spoken to one, two, or among many people. It can be carried out after a short speech, or consecutively, sentence by sentence, or as chuchotage (whispering) aside from notes taken at the time, no equipment is used.9

2.4 The Concept of Simultaneous Interpretation SI has been a key factor in facilitating communication among different cultural and linguistic groups, thereby contributing to the establishment of the modern global economy. 
The SI medium delivers a very important message that the complete involvement of each delegate is highly valued and essential to the success of the conference. SI is necessary for effective communication in many situations, and is often expected by conference delegates. 10

The definition of SI in simultaneous mode means interpreter sits in a booth with a clear view of the meeting room to listen the speaker and simultaneously interprets the speech into a TL. Simultaneous interpreting requires a booth (fixed or mobile) that meets ISO standards of acoustic isolation, dimensions, air quality and accessibility as well as appropriate equipment such as: headphones and microphones Association International Interpreters Conference (henceforth AIIC).11 Interpreting process starts while the delegate is speaking and the interpreter works in a soundproof booth with at least one colleague. The speaker in the meeting room speaks into a microphone; the interpreter receives the sound through a headset and renders the message into a microphone almost simultaneously. The delegate in the meeting room selects the relevant channel to hear the interpretation in the language of his/her choice. There are many different possible configurations of languages or language regimes:

- $\quad$ Simultaneous Interpreting means listening and speaking at the same time.

- That also means high requirements concerning the active and passive mastering of the working languages.

- $\quad$ Studies show that the lapse of time after which the interpreter starts rendering his version is about two to three seconds.

- $\quad$ The ideal speaking velocity of the orator is about 100 to 120 English words for the interpreter.

Simultaneous interpreter must not succumb to the lexical, syntactical and stylistic influence of the SL. The same is true for metaphors, sayings. Generally, these interferences are less important in the mother tongue than in the TL.12 Interpretation is called consecutive or simultaneous interpretation or translation, like all other forms of communication, is a multifaceted activity. It involves a sender, a channel, and a recipient. It is a form of communication between people with different linguistic and cultural backgrounds. 13

Other expectations require that interpreters think fast, have strong short term memory, and be able to work under physical and mental pressure for long periods of time.14 The professional interpreters have realised that the process of interpretation is a challenging task. A task that requires various types of both linguistic, nonlinguistic skills, mastery of the active language, solid background of general knowledge, some personal qualities like the faculty of analysis and synthesis, the ability to intuit meaning, the capacity to adapt immediately to change in subject matter, and different speakers and situations. Other qualities include the need to have good short and long-term memory, the ability to concentrate, a gift for public speaking, and physical endurance and good nerves.

Moreover, simultaneous interpretation may be clarified as an automatic mental and somatic act, more like an unconscious process the brain and mind would operate during swimming and driving. When we try to make it all conscious, we interfere with what the automatic part of brain would do, and that makes it slow and inaccurate.

\subsection{Qualifications of Simultane ous Interpretation}

The process of SI is one of the accurate tasks in rendering and delivering the message from the SL to the TL, thus, most of the specialists utilize their experiences to clarify the characteristics of a good interpretation. One of those is Buhler15 when he puts the first criteria on quality expectations for SI process, quality criteria are 
grouped in "linguistic semantic" and "extralinguistic pragmatic".

The "linguistic semantic" criteria are presented in native accent, pleasant voice, fluency of delivery, logical cohesion of utterance, sense consistency with original message, completeness of interpretation, correct grammatical usage, use of correct terminology, use of appropriate style. While the "extra-linguistic pragmatic" criteria are presented thorough preparation of conference documents, endurance, poise, pleasant appearance, reliability, ability to work in a team, positive feedback from delegates.

Buhler reveals regarding to an accurate study for those criteria that the "linguistic" criteria receive the highest ratings from respondents: sense consistency with original message is the first, followed by logical cohesion of utterance, completeness of interpretation, use of correct terminology, correct grammatical usage, and fluency of delivery. The criterion reliability receives the highest rating among "extralinguistic" criteria, followed by thorough preparation of conference documents and ability to work in a team. The criteria of native accent, pleasant voice, use of appropriate style, endurance, poise and pleasant appearance are considered a desirable in most cases but not essential.16

Interpreting proficiency does not ensure by linguistic ability itself. High levels of culture and education are required. The interpreters' background has to be broad enough to include a wide range of vocabulary and an ability to assimilate a variety of subjects. The best results are achieved when the interpreters have spent several years in the countries of both languages, for instance, if they had received their education in the native country and had professional experience in a foreign country. Other criteria that indicated good candidates for interpreting were a professional background in law and public speaking on experience.
Finally, the Translation Division was looking for skills that were required specifically for simultaneous interpreting. Given the stressful conditions of the job, interpreters had to have self-composure under pressure and the ability to concentrate in difficult situations. The job required the mental agility to hear and speak at the same time, and to adapt instantaneously to the stimulus of the SL. This means that interpreters have to be able to quickly find an alternative if the best translation does not come to mind, as they are not supposed to stutter or stop. They have to be able to make decisions quickly and accurately. The job also requires great mental and physical efforts because of the need to interpret both speedily and accurately, and to adapt to the speed of the speaker. Finally, interpreters require having a good voice and clear enunciation, so that it can be easy to listen to them for hours at a time. It reports that the division removed "several interpreters whose speech habits make listening to them most uncomfortable in the long run".17

Moreover, one of the quantity qualifications of SI is the equipment, which can be used to ensure the ability of individuals who speak variety of languages, concerning to the learning and hearing of the same massage. Generally, SI equipment consists of a transmitter, a set of headsets, and receivers. SI equipment can use both, indoors and outdoors in a variety of ways: - to help hard-of-hearing learners participate fully.

- to enable a teacher to talk very quietly when necessary.

- to allow people who speak different languages to hear a presentation at the same time as English speakers.

The first two activities do not require another person to interpret the programme. Interpreters use interpretation equipment to share what a speaker says with participants who speak a different language, usually the speaking at the same time of the presenter is called 
Simultaneous Interpretation, and it differs from only going back, and from between two languages, as a bilingual presenter may do. 18 An example of SI would be a presenter speaks in English while an interpreter is talking into a small transmitter, interpreting the presentation at once into Kurdish. Kurdish speakers then hear the interpreted presentation with their small headsets and receivers. In this case, both English and Kurdish speakers in the group hear the discourse at the same time in their preferred language.

\subsection{Difficulties and Problems of}

\section{Simultaneous Interpretation}

Generally, translation as well as interpretation difficulties and problems can be clarified as 'any difficult or problem that make translators/interpreters stop twice. First stop is due to a difficult or problem, and second stop to think how to solve and tackle it. Ghazala19 states linguistic problems like; grammatical, lexical, stylistic and phonological problems. Regarding grammatical difficulties and problems, he mentioned complicated SL, different TL grammar, different TL order. Concerning lexical problems; literal translation, synonym, idioms, and ESP terminologies are serious difficulties. Stylistic problems deal with formal vs. informal language, parallelism, ambiguity, and complex vs. simple style. Moreover, phonological difficulties involve homophonic words, incorrect pronunciation, and sometimes maybe unpleasant voice.

The process of translation and interpretation are faced non-linguistic difficulties and problems besides linguistics' ones. Personality difficulties are considered serious obstacles in front of a good translation and interpretation; here some of those difficulties and problems like lack of endurance, poise, punctuality, flexibility, and active listening and memorization skills. Seleskovitch20 states that lacking active listening and memorization skills of interpreter as an obstacle, because the crucial task of an interpreter is listening to two speakers at the same moment, first speaker who speaks SL, while second speaker an interpreter him/herself, in this case the difficult is the distraction. This is the complexity the job of the interpreter.

Diversity of SL and TL cultures is another type of difficulties and problems. Al-Hamadani21 clarifies that translation is a crucial vehicle for intercultural exchanges. Translating from culture to culture means exposing receptors to new ideas and facts in the TL culture broaden their cultural horizons, make them aware that other people may have different symbols, customs and beliefs, which other cultures should respect and know. However, copious details regarding the cultural differences influencing translation process between communities have dealt with in great number of publications.

Based on Casagrande's22 formula: 'one does not translate LANGUAGES only but CULTURES also', because many translation problems arise due to the symbolic actions in the SL culture which are absent in the TL culture or have different meanings there. The ability of the receptors to understand and overcome cultural differences in receiving the source text message should not be underestimated. To understand a message means interpreting it according to the background knowledge. When such knowledge is missing due to cultural differences, the translator renders, as Venuti23 and Kussmaul24 see, the TL with what the words in the original message mean in their SL culture. The translator must provide additional information in the TL to compensate for the lack of the background knowledge shared by the receptor in the SL. This is part of the translator's aim to bring the original message over to the TL receptor.

It is worthy to mention technical difficulties and problems. This type is concerned the setting (time and place) of the interpretation rather than translation. Regarding the time, unfamiliarity the topic of interpretation beforehand, shortage 
permitted time for interpreting, speaker's fast speech, continuous long times of interpreting. All those and others are effected on the quality of interpretation.

Concerning real observations for the settings of the SI by the researcher, there are many difficulties and problems are discovered. SI requires high concentration, normally at least, two interpreters working in a booth who will take their turn every ten to thirty minutes, according to the difficulty of the speeches, language combination, and velocity of the speaker. The work of the interpreter may become more difficult through external factors:

1. Small booth without sufficient air

2. Poor light in the booth

3. Poor or no sight on the conference room

4. Poor microphone discipline of the speaker

5. Reading out of texts not available to the interpreter

\section{Methodology}

The tools that are used in this study are a focus group of an interview and a questionnaire. The focus group is used for collecting data and to reach to exact and detailed information and knowledge about the intended topic. The second tool questionnaire was designed depending on the focus group.

\subsection{Monitoring the Focus Group of an Interview}

Focus group is a first tool in this study, it can be defined as 'a group takes shape the synergistic dynamics of participants responding to and building on each other's view'.25 A focus group is a small, but demographically diverse group of people and whose reactions studied specific domains are marketing, political, social, and humanities studies. It is guided or opened discussions about a new product or something else to determine the reactions that can be expected from a larger population. It is a form of qualitative research consisting of interviews in which a group of people is asked about their perceptions, opinions, beliefs, and attitudes towards a product, service, concept, advertisement, idea, or packaging. Questions are asked in an interactive group setting where participants are free to talk with other group members. During this process, the researcher either takes notes or records the vital points s/he is getting from the group. Researchers should select members of the focus group carefully for effective and authoritative responses. 26

Focus groups are groups of typically six to twelve participants; they are setting to gather to engage in a debate that is, centered on a specific number of issues. The debate continues nearly one to two hours when conducted face to face. Focus groups are similar to collective interviews, but there is greater focuses on the interactive nature of the activity. 27

The focus group of an interview of the study is involved two categories statements, to cover a wide extent of the linguistic and nonlinguistic factors of SI, see (appendix A). Moreover, the focus group is a qualitative means of study, so it does is not need to treat it statistically; the benefit of focus group is to provide and enrich the study with great amount of data and information about SI to use it for designing and constructing the tools of study. Moreover, the same sample of the focus group are suggested suitable solutions for those difficulties, which are diagnosed before (see appendix B). see table (1)

\subsection{Designing the Questionnaire}

The second tool of the study is a questionnaire. It was designed depending on the focus group. The latter is considered the material for the items of the questionnaire. Questionnaire is defined as 'a list of questions that are answered by many people. A questionnaire is used to collect information about particular subject.28 Also it can be defined as 'a list of questions each with a range of answers, a format that enables standardised, relatively structured, 
data to be gathered about each of a large number of cases'.29 Questions can be asked and data recorded in various ways. Different kinds of questions may be appropriate for different aims and various types of data. Generally, there are three types of questions, which are asked the respondent to reply; closed or opened, spontaneous or promoted, open-ended or precoded.

The intended questionnaire is involved linguistic, as well as, nonlinguistic factors. More specifically, the area of linguistic factors are involved all the linguistic aspects like; syntax, semantics, pragmatics, language skills, and phonetics. While the nonlinguistic factors are included; the personal features of simultaneous interpreter, ceremony's' details, and other nonlinguistic factors. The questionnaire is consisted of 27 items, all those items dealt with difficulties and problems of SI. It is submitted to thirty simultaneous interpreters in Kurdistan Region, table (2) reveals the characteristics of questionnaire items' respondents, (see appendix C). See table (2)

\section{Procedures of Data Analysis}

To get precise results after using two evaluative tools, focus group of interview and questionnaire, the following statistical analyses are done as follow:

\subsection{Analysis of Focus Groups' Data}

After two sessions with the twelve members of the focus group, an amount of knowledge and information have been gotten about difficulties and problems of SI as well as solutions for those difficulties, (see appendix $A \& B$ ), analysing the data collected from a focus group of interview has been done by getting the percentage its items.

\subsubsection{Items of Difficulties of the Focus Group}

Analysing the items of the difficulties of the focus group (appendix A) is dealt with by obtaining the percentage that shows the following results, as in table (3) below:See table (3)

Difference of habits, cultures, and attitudes have got the higher degree of the difficulties, which face simultaneous interpreters, it got $75 \%$. Really, the differences in habits, cultures, and attitudes have great effect on the quality of interpreting. Qualified interpreter have to be familiar with habits, cultures, and attitudes of both languages, source language (henceforth SL) and target language (henceforth TL). For example: The $\operatorname{dog}$ at the door. This sentence gives the meaning of threating according to the American English culture and attitude. Again, differences of structures between languages have got the second level, with 58\%. English passive sentence structure is $\mathrm{O}+\mathrm{V}+\mathrm{V}$, qualified interpreter should focus on the object of the sentence during s/he interpreting into Kurdish.

The same thing happened with dialect ambiguity, which came at the third level with $50 \%$. Homophonic words came at the fourth level, 41\%. Phonetics difficulties 33\%, quickness $25 \%$, time shortages $25 \%$. Nonprofessional speaker, missing words during interpreting, lack of experience, lacking professional training, insufficient thematic knowledge, idiomatic expressions, new idioms and expressions, unsuitability of the settings, all these have got the same level of difficulties 17\%. Syllabus lacking of SI, audiences' questions during interpreting, lack of international terms, sound system problems, lacking equipment of SI, Divine questions like that in the Qur'an, long speeches, these difficulties have got the lower level of difficulty $8 \%$.

\subsubsection{Items of Solutions of the Focus Group}

After diagnosis the difficulties of SI, the same members of a focus group have been suggested several solutions for those difficulties and 
problems (appendix B), which are analysed as shown in table (4): See table (4)

The first solution suggested by a focus group is finding suitable terminologies, which was got higher level as a solution $66 \%$. This solution may be tackle several difficulties like; Difference of habits, cultures, and attitudes. Familiarity with different ideological and cultures, paraphrasing, improving memory skills, these solutions were got second level $41 \%$. Moreover, knowing the topic beforehand was got $33 \%$, patience and resilience with focusing on the idea were got $25 \%$, ensuring technical equipment are available and fluently speaker were got $17 \%$, doing research, talking with delegates beforehand, arranging and sitting levels of SI horizontally and vertically, improving listening skills, idioms, these solutions were got lower level $8 \%$.

\subsection{Analysis of Questionnaires' Data}

After collecting amount of information about difficulties and suggested solutions for those difficulties, a semi-structured questionnaire was designed (see appendix C\&D). This questionnaire was submitted to thirty simultaneous interpreters in Kurdistan Region-Iraq, to obtain their beliefs and perspectives about those items of difficulties as well as their solutions. Two statements were involved in the questionnaire, the first consists from twenty-seven items of difficulties, and the second consists from twenty-three items of solutions of difficulties. Analysing the collecting data of the questionnaire has been done by getting the results statistically.

\subsubsection{Items of Difficulties of the Questionnaire}

The results are arranged from the highest degree of the importance to the lower one, according to simultaneous interpreters' perspectives towards difficulties of SI, (M= 4.43-3.33) as shown in table (5) below: See table (5)
The results of the first item shows that; speaker fast speech, 90\% ( $\mathrm{M}=4.43)$ of the simultaneous interpreters, (henceforth SIs), agree that they are effected by fast speech of speaker during their interpretation, so it is a real difficulty and problem. Regarding item (2), sound system problems, 93\% ( $\mathrm{M}=4.40)$ of the SIs agree that sound system problems like; echoes, sudden stopping sounds, etc., are real problem and one of the difficulties of SI process. Any sounds problems will lead to lagging behind of SIs.

Concerning item (3), inactive listening, 93\% $(\mathrm{M}=4.33)$ of the SIs agree that inactive listening of the interpreters is a serious difficulty, since there is no enough time for thinking or memorising what the speaker said. The reason behind that is that the crucial task of simultaneous interpreter is to render and deliver the message from SL into TL with a minimal analysis time. Concerning item (4), lack of knowledge about topic events, 93\% (M=4.27) of the SIs agree that they need any knowledge or information about the topic of interpretation beforehand, unless there is difficulty to start with a topic without preparing something before.

Concerning item (5), lack of experience, 93\% ( $\mathrm{M}=4.23)$ of the SIs agree that experience is very important in SI, because the process of SI is involved numbers of skills, and those skills with progressive will change and move to be habits, all those because of experience, so lack it is a difficult and problem. Concerning item (6), inaccurate pronunciation, $93 \%(\mathrm{M}=4.20)$ of the SIs agree that wrong or unclear pronunciation is a difficult; because it leads the simultaneous interpreter to misunderstanding, then the production will be incorrect.

Concerning item (7), long boring sentences, 90\% ( $\mathrm{M}=4.20)$ of the SIs agree that long boring sentences is a difficult and problem during SI, the reason that the SIs have not time to concentrate on the parts of a sentence if it was a complex sentence, besides to focus on series of 
complex sentences. The allowed ISO standard time for waiting is just three minutes, after this permission the production will be trivial. Concerning item (8), misuse of terminological expressions, $93 \%(\mathrm{M}=4.13)$ of the SIs agree that unqualified speaker in using correct and accurate expressions lead to face a difficult in interpreting.

Concerning item (9), ambiguous speech, 93\% (M=4.13) of the SIs agree that ambiguity of speech difficult in SI. The real task of SIs is not changing the meaning from language to another, but it is communicating the message from SL into TL, rendering the intended meaning from the producer to the receptor. Concerning item (10), Cultural diversity, 83\% ( $\mathrm{M}=4.10)$ of the SIs agree that varieties of cultures between the speaker (producer), and the audience (receptor) is formed a difficult for the interpreter. Based on Casagrande's ${ }^{30}$ formula: "one does not translate LANGUAGES only but CULTURES also", because many translation problems arise due to the symbolic actions in the SL culture which are absent in the TL culture or have different meanings there. The ability of the receptors to understand and overcome cultural differences in receiving the source text message should not be underestimated.

As for item (11), ESP terminologies, $80 \%$ $(\mathrm{M}=4.10)$ of the SIs agree that using vocabulary for specific purposes makes interpreter in difficult situation, because of diversity of the meaning from field to another. Regarding item (12), Audience interruption within interpretation, $83 \%(\mathrm{M}=4.10)$ of the SIs agree that the interpreter is affected by the interruption, annoying, and crowded of audience in the setting of interpreting. This difficulty is derived from another difficulty, it is lacking of building booth, mostly there are mobile booth not building, therefore, the interpreter face this problem.

Concerning item (13), lack of endurance, $83 \%(\mathrm{M}=4.06)$ of the SIs agree that interpreter should be enduring, due to there is no comfort time during interpreting, besides other sudden problems like; lacking his/her boothmates in embarrassing situation. In item (14), lack of international terms, $84 \%(\mathrm{M}=4.06)$ of the SIs agree that there are international vocabulary, which are used globally for each decade, lacking those words is difficult, so an interpreter have to be aware for the importance of those terms.

Regarding item (15), ill-formed sentences, $83 \%(\mathrm{M}=4.06)$ of the SIs agree that those sentences of speaker, which not structured welled will make the interpreter in difficult situation. ill-formed sentences means using sentences out of the structure of its language. Regarding item (16), newly-coined idiomatic expressions, $83 \%(\mathrm{M}=4.03)$ of the SIs agree that sometimes interpreter faces new-born idioms and expressions, which are not heard before, this will make him/her in difficulty.

Regarding item (17), shortage of time, $83 \%$ $(\mathrm{M}=4.03)$ of the SIs agree that lacking enough time to think in a message before rendering it into target is a difficult, standard allowed time is just three minutes. Regarding to item (18), Inability of team working, $76 \%(\mathrm{M}=4.00)$ of the SIs agree that inability to work within your team of interpreter is difficulty, and may be caused real problems for his/her boothmates. What is mentioned in item (12) belong to this item.

Concerning item (19), the use of lexical items out of place, $83 \%(\mathrm{M}=3.97)$ of the SIs agree that sometime the speaker uses lexical (dictionary) items in incorrect place. Mostly, this case may be happened either the speaker is not native, or s/he is not well-educated (rich) in the language. Regarding item (20), homophonic words, $77 \% \quad(\mathrm{M}=3.87)$ of the SIs agree that homophones are real difficult, since there is no written and seen text like translation, it is interpreting the spoken SL into TL. Moreover, the interpreter just hears the speech without seeing, so 
Regarding item (21), Insufficient thematic knowledge, $80 \%(\mathrm{M}=3.87)$ of the SIs agree that interpreter should have a good knowledge about the intended theme that $\mathrm{s} / \mathrm{he}$ will communicate. Thus, it is very important for preparing specialized interpreter, to avoid this difficulty. What is worthy to mention here that in Kurdistan Region-Iraq there are encyclopaedic interpreter, there are not specialized interpreter. Regarding item (22), Unsuitable atmosphere of place and time for interpretation, $73 \%(\mathrm{M}=3.87)$ of the SIs agree that suitable atmosphere very important, time, place, audience, etc. unsuitable of those will effect on the performance of the interpreter, which leads into wrong rendering and communicating of message.

In item (23), Variability of religious concepts, 63\% ( $\mathrm{M}=3.77)$ of the SIs agree that this point also difficult. Variability of religious concepts means using the same religious term but in different situations, depending on the necessity of usage. May be this point a big problematic difficulty, but it got this lower percentage $63 \%$, comparing to the formers due to its few using in public interpreting settings. Preparing specialized (field) of interpreters is a necessary task. Concerning item (24), unforeseen terms, $77 \%(\mathrm{M}=3.77)$ of the SIs agree that unexpected terms makes interpreter in a difficult situation. The difficulty comes here that there is no time for asking or take notes to check it, the permitted maximum time is only three seconds.

Regarding item (25), Word order differences between $S L$ and $T L, 60 \%(\mathrm{M}=3.73)$ of the SIs agree that the differences in syntax, (grammatical arrangement of words), is difficult point for interpreter. For instance, the word order for the English sentence is $(\mathrm{S}+\mathrm{V}+\mathrm{O})$, while the sentence in Kurdish has such order as $(\mathrm{O}+\mathrm{S}+\mathrm{V})$. This claimed maybe is not strong, since SI deals with communicating a message from language to another rather than rendering the meaning of the words from SL into TL.
Regarding item (26), unpleasant voice, $43 \%$ $(\mathrm{M}=3.33)$ of the SIs agree that unpleasant voice of the speaker is a difficult, but it is not a big, since it does not effect on the pronunciation of the words. This point belongs to psycholinguistics. It has its effectiveness on the interpreter may be unconsciously. Regarding the last item (27), embarrassing situations, 50\% $(\mathrm{M}=3.33)$ of the SIs agree that embarrassing words and sentences make the interpreter in difficult situation. Mostly this happened in the political, ethnics, religious, and racism speeches and discussions.

\subsubsection{Items of Solutions of the Questionnaire}

The results of suggested solutions for difficulties and problems of SI according to simultaneous interpreters' beliefs and perspectives are arranged according to their importance from top to bottom, the degrees between $(M=4.53-3.56)$ as shown in table (6) below: See table (6)

After syntactic analysis of the simultaneous interpreters' respondents about the solutions for SI difficulties, and obtaining the means and standard deviation for each item, with agreement percentage, the following results will show in table (7): See table (7) To sum up the suggested solutions, which are presented by the professional interpreters for each difficulty. Table (7) clarifies that each difficulty may have more than one solution to solve and tackle the intended difficulty and problem. Regarding difficulty (1), Speaker fast speech, there are four key points for who speaks fast, without giving attention to the interpreter, who interprets and communicates the messages at the same moment of speaking. The first important tackle is being well-experienced. Experience is a very important factor for an interpreter, by experience the process of receiving the message (SL) rapidly become familiar to the interpreter, who used to hear and listen comprehendingly several hours every day to the speaker, then within times, this familiarization of Speaker fast speech moves to be a habit. Improving listening skills is 
another factor for tackling fast speaker. In every language there are four essential skills; reading, writing, listening, and speaking. Listening is an advanced skill; it comes after familiarisation with first two skills; reading and writing. Why it is called improving listening skills not skill? Because there are number of skills are effected the listening, especially, listening of an interpreter should be comprehension listening. Skills of focusing/concentration, giving attention, imagining, and having expanded fancy, all these are considered components of listening skills. For this reason is called listening skills. Knowing the topic beforehand is necessary when the interpreter miss and loss some words or expressions because of speaker's fast speech, and listening actively helps interpreter to be ware in his/her listening, especially with the fast one.

The rest difficulties will be solved and tackled with the same way. Concerning last item (28), all difficulties is tackled by doing research. Off course, solving any problem, and tackling any difficulty depends on a scientific study in its field to reach to the intended purposes. Thus, doing research as a solution is beneficial and it is used for single difficulty, as well as, all generally.

The researcher supports his argument by referring to these sources; Ghazala31, Poyatos32, Casagrande33, Buhler34, and Laurion and Skora35. They state "although simultaneous interpreters have relatively positive perceptions on the mentioned difficulties and problems, and at the same time, they have the same perspective on the solutions, but they are still suffer from those difficulties, and they need the support from official institutes to improve the process of SI in Kurdistan Region-Iraq".

Moreover, the researcher compares the Mean of the interpreters' respondents of the questionnaire about the items of difficulties as well as the suggested solutions for those difficulties to find out the differences with hypothetical mean, which is (3), the results reveals that there are significant differences at $0.0,5$ level for the all items, regarding (t. value $\&$ p. value).

The purpose of the simultaneous interpreters' questionnaire was to gauge impressions of their professional experiences. Owing to the standard deviation (SD), of the difficulties items ranging from (0.55) to (1.12), and of the solutions items ranging from $(0.47)$ to (1.07). The results revealed that the simultaneous interpreters have agreement with each other about diagnosis the difficulties as well as suggested suitable solutions for it.

The quantitative results obtained from the simultaneous interpreters' focus group of the interview and the questionnaire about difficulties and problems of SI, as well as the suggested problems revealed the impression that the simultaneous interpreters' Kurdish have qualified and professional in their tasks and performance of SI. They got excellent perspectives as well as knowledge towards SI.

\section{Conclusions and Recommendations}

The conclusions arrived at throughout this study can be summed up as follows:

- There are clear differences between translation and interpretation, according to qualifications, requirements, difficulties, problems, and so on.

- SI is a crucial task, since it deals with the intended meaning of the speaker. The job of interpreter is communicating the message from one language to another.

- There are significant differences at 0.0,5 level for the linguistic and non-linguistic items of difficulties and problems, which stand as an obstacle in front of good interpreting like; difference of habits, cultures, and attitudes, differences of structures between languages, dialect ambiguity, and homophonic words, 
quickness of speaker, time shortage of SI, lack of experience, lacking professional training.

- There are significant differences at 0.0,5 level for all linguistic and non-linguistic items of solutions for difficulties, which are stand as obstacle in front of good interpreting like; being well-experienced, improving listening skills, knowing the topic beforehand, and listening actively .

There is a number of the recommendations that would be useful if they are achieved:

- Nowadays the process of SI is a profession and a job rather than to be a scientific or an academic process.

- Diagnosing difficulties, problems, and obstacles of SI

- Finding out the suitable solutions for those difficulties, problems, and obstacles of SI

- Doing and establishing studies to search and study each difficulty and problem of SI separately, then finding out suitable solution for it.

- Participating simultaneous interpreters in primary as well as professional training courses of SI

- Giving attention to syllabus of translation in translation and English departments in the faculties and universities of Kurdistan

- Supporting and helping translation associations in Kurdistan by; establishing, looking attention, supporting, and supervising by official/government professionals specialists

\section{References}

1. K. Malmkjer and K. Windle, Translation Studies (New York: Oxford University Press, 2011), 275.

2. S. Dodd, How to Become Interpreter and Translator: A Beginner's Guide. $1^{\text {st }}$ Edition. (The English Press, 2012), 4

3. F. Gaiba, The Origins of Simultaneous Interpretation: The Nuremberg Trial. (Ottawa: University of Ottawa Press, 1998), 25-29.
4. A. Cincan, "The Challenges of Simultaneous Interpretation" (Unpublished Article, 2012), 55.

5. Ibid., 49.

6. Dodd, 7.

7. Ibid., 9 .

8. Ibid., 8 .

9. Ibid.

10. Ibid., 66.

11. AIIC, "Practical Guide for Professional Conference Interpreters" (Geneva: AIIC Press, 1990), 45.

12. P. Fawcett, Translation and Language (Manchester, Northampton, 2003), 35.

13. H. Qian, On the Implausibility of Equivalent Response. Part ii. Meta, vol. 37, no. 3. (1994), 214.

14. M. Qzar, "The Role of Memory as a Cognitive Psychological Faculty in Simultaneous Interpretation" (Unpublished M.A. Thesis, ALYarmouk University, Jordan, 1997), 67.

15. H. Buhler, "Linguistic (Semantic) and ExtraLinguistic (Pragmatic)" in Criteria for the Evaluation of Conference Interpretation and Interpreters (1986), 233.

16. Ibid.

17. Gaiba, 46-47.

18. L. Laurion and R. Skora, Simultaneous interpretation Equipment. (2014), 1.

19. H. Ghazala, Translations as Problems and Solutions. A Course for University Students and Trainee Translators. (Elga Publication 1995), 18.

20. D. Seleskovitch, Language and Cognition (New York: Plenum Press, 1978), 30-31.

21. A. Al-Hamadani, "The Cultural Gaps Resulted in Translating Some Selected Arabic Proverbs into English." (Unpublished Research, 2018), 1-10.

22. J. Casagrande, The Ends of Translation (Oxford: Oxford University Press, 1955), 4.

23. L. Venuti, The Translation Studies Reader (London \& New York: Routledge, 2000), 30. 
24. P. Kussmaul, Training the Translator (Amsterdam: Rodopi, 1995), 57.

25. N. Edley and L. Lia, "Contemplating Interview and Focus Groups" in Research Methods in Linguistics, ed. Lia Litosseliti (London and New York: Continuum, 2010), 167.

26. U. Jump, "Definition of Focus Group in US English by Oxford Dictionaries". Oxford Dictionaries - English. 2007, (Retrieved May 2018), 66.

27. Ibid, 173.

28. S. Weheier, Oxford Word Power Dictionary (Oxford: Oxford University Press, 1993), 504.

29. G. Saldanha, and S. O'Brien, Research Methodologies in Translation Studies (Manchester: St. Jerome Publishing, 2013), 151.

30. Casagrande, 4.

31. Ghazala, 18.

32. F. Poyatos, Nonverbal Communication and Translation: New Perspective and Challenges in Literature, Interpretation, and the Media (Amsterdam: John Benjamin Publishing Company, 1997), 69.

33. Casagrande, ibid.

34. Buhler, 233.

35. Laurion and Skora, 1.

\section{Bibliography}

Al-Hamadani, A. "The Cultural Gaps Resulted in Translating Some Selected Arabic Proverbs into English." Unpublished Research, 2018.

AIIC. "Practical Guide for Professional Conference Interpreters. Geneva: AIIC Press, 1990.

Buhler, H. "Linguistic (Semantic) and Extra-Linguistic (Pragmatic)." In Criteria for the Evaluation of Conference Interpretation and Interpreters. Multilingual, 1986.

Casagrande, J. The Ends of Translation. Oxford: Oxford University Press, 1955.

Cincan, A. "The Challenges of Simultaneous Interpretation.” Unpublished Article, 2012.
Dodd, S. How to Become Interpreter and Translator: A Beginner's Guide. The English Press 4735/22 Prakashdeep Bldg, 2012.

Edley, N. and Lia, L. "Contemplating Interview and Focus Groups." In Lia Litosseliti (ed.) Research Methods in Linguistics. London and New York: Continuum, 2010.

Fawcett, P. Translation and Language. Manchester, 2003.

Gaiba, F. The Origins of Simultaneous Interpretation: The Nuremberg Trial. Ottawa: University of Ottawa Press, 1998.

Ghazala, H. Translations as Problems and Solutions. A Course for University Students and Trainee Translators. Elga Publication 1995.

Gregoris, G. "The Limits of Expectations Vs. Assessment Questionnaire-Based Surveys on Simultaneous Interpreting Quality: The Need for a Gestaltic Model of Perception." University Trieste gregorio.degregoris@phd.units.it. 2005.

Kussmaul, P. Training the Translator. Amsterdam: Rodopi, 1995.

Laurion, L. and Skora, R. Simultaneous Interpretation Equipment. 2014.

Malmkjer, K. and Windle, K. Translation Studies. New York: Oxford University Press, 2011.

Poyatos, F. Nonverbal Communication and Translation: New Perspective and Challenges in Literature, Interpretation, and the Media. Amsterdam: John Benjamin Publishing Company, 1997.

Qian, H. "On the Implausibility of Equivalent Response.” Part ii. Meta. vol. 37, no. 3 (1994):

Qzar, M. "The Role of Memory as a Cognitive Psychological Faculty in Simultaneous Interpretation.” Unpublished M.A. Thesis, ALYarmouk University, Jordan, 1997.

Jump, U. "Definition of Focus Group in US English by Oxford Dictionaries." Oxford Dictionaries English. Retrieved May 2018.

Saldanha, G. and O'Brien, S. Research Methodologies in Translation Studies. Manchester: St. Jerome Publishing, 2013.

Seleskovitch, D. Language and Cognition. New York: Plenum Press, 1978.

Venuti, L. The Translation Studies Reader. London \& New York: Routledge, 2000.

Weheier, S. Oxford Word Power Dictionary. Oxford: Oxford University Press, 1993. 
Table (1)

Characteristics of Focus Groups' Respondents

\begin{tabular}{|c|c|c|c|c|}
\hline No. & Gender & Degree Held & Experience Years & Specialization \\
\hline 1 & Male & M. A. & 30 & Applied Linguistics \\
\hline 2 & Male & M. A. & 20 & English / Literature \\
\hline 3 & Male & B. A. & 15 & English \\
\hline 4 & Male & M. Sc. & 15 & International Economics \\
\hline 5 & Male & M. A. & 14 & English / linguistics \\
\hline 6 & Male & Ph. D. & 13 & English / Translation \\
\hline 7 & Male & b. A. & 13 & English / Translation \\
\hline 8 & Male & B. A. & 13 & English \\
\hline 9 & Male & B. A. & 13 & English \\
\hline 10 & Male & B. A. & 13 & English \\
\hline 11 & Male & Ph. D. & 10 & English / Literature \\
\hline 12 & Male & M. A. & 10 & \\
\hline
\end{tabular}

Table (2)

Characteristics of Questionnaires' Respondents

\begin{tabular}{|c|c|c|c|c|}
\hline No. & Gender & Held Degree & Experience Years & Specialization \\
\hline 1 & Male & M. A. & 30 & Applied Linguistics \\
\hline 2 & Male & M. A. & 20 & English / Literature \\
\hline 3 & Male & B. A. & 15 & English \\
\hline 4 & Male & M. Sc. & 15 & International Economics \\
\hline 5 & Male & M. A. & 14 & English / linguistics \\
\hline 6 & Male & Ph. D. & 13 & English / Translation \\
\hline 7 & Male & b. A. & 13 & English / Translation \\
\hline 8 & Male & B. A. & 13 & English \\
\hline 9 & Male & B. A. & 13 & English \\
\hline 10 & Male & B. A. & 13 & English \\
\hline 11 & Male & Ph. D. & 10 & English / Translation \\
\hline
\end{tabular}




\begin{tabular}{|c|c|c|c|c|}
\hline 12 & Male & M. A. & 10 & English / Literature \\
\hline 13 & Male & M. A. & 10 & English / Applied \\
\hline 14 & Male & M. A. & 10 & English / Translation \\
\hline 15 & Male & M. A. & 10 & Political Sciences \\
\hline 16 & Male & B. A. & 10 & English \\
\hline 17 & Male & M. A. & 9 & English / Literature \\
\hline 18 & Male & Ph. D. & 8 & English / Translation \\
\hline 19 & Male & M. A. & 8 & English / Translation \\
\hline 20 & Male & B. A. & 7 & English \\
\hline 21 & Male & M. A. & 5 & English / Linguistics \\
\hline 22 & Male & M. A. & 5 & English / Translation \\
\hline 23 & Female & B. A. & 5 & Architecture Engineer \\
\hline 24 & Male & M. A. & 5 & English / Literature \\
\hline 25 & Male & M. A. & 4 & English / Applied \\
\hline 26 & Male & Undergraduate & 4 & IELTs Certification \\
\hline 27 & Male & B. A. & 4 & English \\
\hline 28 & Male & B. A. & 3 & English \\
\hline 29 & Male & B. A. & 2 & English \\
\hline 30 & Male & M. A. & 2 & English / Linguistics \\
\hline
\end{tabular}

Table (3)

Analysis Difficulties of the Focus Group

\begin{tabular}{|c|c|c|c|}
\hline Difficulty & $\begin{array}{c}\text { \% of } \\
\text { agreement }\end{array}$ & Difficulty & $\begin{array}{c}\text { \% of } \\
\text { agreement }\end{array}$ \\
\hline syllabus lacking of SI & $8 \%$ & lack of experience & $17 \%$ \\
\hline $\begin{array}{c}\text { difference of habits, } \\
\text { cultures, and attitudes }\end{array}$ & $75 \%$ & sound system problems & $8 \%$ \\
\hline Quickness & $25 \%$ & lacking equipment of SI & $8 \%$ \\
\hline dialect ambiguity & $50 \%$ & lacking professional training & $17 \%$ \\
\hline time shortages & $25 \%$ & $\begin{array}{c}\text { insufficient thematic } \\
\text { knowledge }\end{array}$ & $17 \%$ \\
\hline phonetics difficulties & $33 \%$ & $\begin{array}{c}\text { Divine questions like that in } \\
\text { the Qur'an }\end{array}$ & $8 \%$ \\
\hline $\begin{array}{c}\text { differences of structures } \\
\text { between languages }\end{array}$ & $58 \%$ & idiomatic expressions & $17 \%$ \\
\hline
\end{tabular}




\begin{tabular}{|c|c|c|c|}
\hline $\begin{array}{c}\text { audiences' questions } \\
\text { during interpreting }\end{array}$ & $8 \%$ & new idioms and expressions & $17 \%$ \\
\hline $\begin{array}{c}\text { lack of international } \\
\text { terms }\end{array}$ & $8 \%$ & unsuitability of the settings & $17 \%$ \\
\hline non-professional speaker & $17 \%$ & homophonic words & $41 \%$ \\
\hline $\begin{array}{c}\text { missing words during } \\
\text { interpreting }\end{array}$ & $17 \%$ & long speeches & $8 \%$ \\
\hline
\end{tabular}

Table (4)

Analysis Solutions for Difficulties of the Focus Group

\begin{tabular}{|c|c|c|c|}
\hline Solution & $\begin{array}{c}\text { \% of } \\
\text { Agreement }\end{array}$ & Solution & $\begin{array}{c}\text { \% of } \\
\text { Agreement }\end{array}$ \\
\hline $\begin{array}{c}\text { finding suitable } \\
\text { terminologies }\end{array}$ & $66 \%$ & patience and resilience & $25 \%$ \\
\hline doing research & $8 \%$ & improving listening skills & $8 \%$ \\
\hline $\begin{array}{c}\text { ensuring technical } \\
\text { equipment are available }\end{array}$ & $17 \%$ & Idioms & $8 \%$ \\
\hline $\begin{array}{c}\text { knowing the topic } \\
\text { beforehand }\end{array}$ & $33 \%$ & $\begin{array}{c}\text { familiarity with different } \\
\text { ideological and cultures }\end{array}$ & $41 \%$ \\
\hline $\begin{array}{c}\text { talking with delegates } \\
\text { beforehand }\end{array}$ & $8 \%$ & Paraphrasing & $41 \%$ \\
\hline $\begin{array}{c}\text { arranging and sitting } \\
\text { levels of SI horizontally } \\
\text { and vertically }\end{array}$ & $8 \%$ & improving memory skills & $41 \%$ \\
\hline Fluently speaker & $17 \%$ & focusing on the idea & $25 \%$ \\
\hline
\end{tabular}

Table (5)

Analysis Difficulties of the Questionnaire

\begin{tabular}{|c|l|c|c|c|}
\hline No. & \multicolumn{1}{|c|}{ Difficulties } & Mean & $\begin{array}{c}\text { Standard } \\
\text { Deviation }\end{array}$ & $\begin{array}{c}\text { \% of } \\
\text { Agreement }\end{array}$ \\
\hline 1 & Speaker fast speech & 4.43 & 0.77 & $90 \%$ \\
\hline 2 & Problems of sound system & 4.40 & 0.62 & $93 \%$ \\
\hline 3 & Inactive listening & 4.33 & 0.61 & $93 \%$ \\
\hline 4 & Lack of knowledge about topic events & 4.27 & 0.58 & $93 \%$ \\
\hline 5 & Lack of experience & 4.23 & 0.68 & $93 \%$ \\
\hline 6 & Long boring sentences & 4.20 & 0.81 & $90 \%$ \\
\hline 7 & Inaccurate pronunciation & 4.20 & 0.55 & $93 \%$ \\
\hline 8 & Ill-formed sentences & 4.13 & 0.90 & $90 \%$ \\
\hline 9 & Ambiguous speech & 4.13 & 0.78 & $83 \%$ \\
\hline 10 & Misuse of terminological expressions & 4.13 & 0.63 & $93 \%$ \\
\hline 11 & ESP terminologies & 4.10 & 0.80 & $80 \%$ \\
\hline
\end{tabular}




\begin{tabular}{|l|l|c|c|c|}
\hline 12 & Audience interruption within interpretation & 4.10 & 0.66 & $83 \%$ \\
\hline 13 & Lack of international terms & 4.07 & 0.91 & $86 \%$ \\
\hline 14 & Lack of endurance & 4.07 & 0.83 & $83 \%$ \\
\hline 15 & Shortage of time & 4.03 & 0.93 & $83 \%$ \\
\hline 16 & Newly-coined idiomatic expressions & 4.03 & 0.72 & $83 \%$ \\
\hline 17 & Inability of team working & 4.00 & 0.91 & $77 \%$ \\
\hline 18 & The use of lexical items out of place & 3.97 & 0.81 & $83 \%$ \\
\hline 20 & Cultural diversity & 3.93 & 0.52 & $83 \%$ \\
\hline 21 & Insuitable atmosphere of place and time for & 3.87 & 1.01 & $73 \%$ \\
\hline 22 & & & \\
\hline 23 & Unfufficient thematic knowledge & 3.87 & 0.86 & $80 \%$ \\
\hline 24 & Variability of religious concepts & 3.87 & 0.68 & $77 \%$ \\
\hline 25 & Word order differences between SL and TL & 3.77 & 1.01 & $77 \%$ \\
\hline 26 & Embarrassing situations & 3.77 & 0.68 & $63 \%$ \\
\hline 27 & Unpleasant voice & 3.33 & 0.98 & $60 \%$ \\
\hline
\end{tabular}

Table (6)

Analysis Solutions of the Questionnaire

\begin{tabular}{|c|l|c|c|c|}
\hline No. & \multicolumn{1}{|c|}{ Solutions } & Mean & $\begin{array}{l}\text { Standard } \\
\text { Deviation }\end{array}$ & $\begin{array}{c}\text { \% of } \\
\text { agreement }\end{array}$ \\
\hline 1 & Listening actively & 4.53 & 0.51 & $100 \%$ \\
\hline 2 & Improving listening skills & 4.53 & 0.63 & $93 \%$ \\
\hline 3 & Improving memorization skills & 4.53 & 0.63 & $93 \%$ \\
\hline 4 & Finding suitable terminologies & 4.30 & 0.47 & $100 \%$ \\
\hline 5 & Endurance & 4.23 & 0.63 & $90 \%$ \\
\hline 6 & $\begin{array}{l}\text { Ensuring availability of technical } \\
\text { equipment }\end{array}$ & 4.20 & 0.71 & $83 \%$ \\
\hline 7 & $\begin{array}{l}\text { Going beyond invisible meaning to the } \\
\text { intended one }\end{array}$ & 4.13 & 0.78 & $83 \%$ \\
\hline 8 & $\begin{array}{l}\text { Knowing the topic beforehand for } \\
\text { preparing }\end{array}$ & 4.10 & 0.55 & $90 \%$ \\
\hline 9 & Working in a team & 4.03 & 0.93 & $83 \%$ \\
\hline 10 & Being well-experienced & 4.03 & 0.89 & $78 \%$ \\
\hline 11 & $\begin{array}{l}\text { Accompanying bilingualism by } \\
\text { biculturalism }\end{array}$ & 3.93 & 0.78 & $83 \%$ \\
\hline 12 & $\begin{array}{l}\text { Having background knowledge about } \\
\text { idioms in general }\end{array}$ & 3.93 & 0.64 & $83 \%$ \\
\hline 13 & Having a rich knowledge about ESP & 3.93 & 0.64 & $83 \%$ \\
\hline 14 & Being acquainted with different dialects & 3.93 & 0.87 & $67 \%$ \\
\hline 15 & Bridging the gap between religious & 3.87 & 0.68 & $87 \%$ \\
\hline
\end{tabular}




\begin{tabular}{|c|l|c|c|c|}
\hline & differences & & & \\
\hline 16 & Talking to the speaker before the event & 3.86 & 0.78 & $80 \%$ \\
\hline 17 & Managing ill-formed sentences & 3.80 & 0.71 & $77 \%$ \\
\hline 18 & Securing suitability of place and time & 3.80 & 0.71 & $63 \%$ \\
\hline 19 & Doing research & 3.73 & 0.87 & $67 \%$ \\
\hline 20 & Being visibly faced to the event relevant & 3.67 & 0.92 & $73 \%$ \\
\hline 21 & $\begin{array}{l}\text { Considering structural differences } \\
\text { between languages }\end{array}$ & 3.60 & 1.00 & $63 \%$ \\
\hline 23 & Coping up with unpleasant tone & 3.53 & 0.78 & $43 \%$ \\
\hline & $\begin{array}{l}\text { Arranging and setting levels of standard } \\
\text { and non-standard SI }\end{array}$ & 3.43 & 1.07 & $64 \%$ \\
\hline
\end{tabular}

Table (7)

Suggested Solutions for Difficulties

\begin{tabular}{|c|c|c|}
\hline No. & Difficulties & Solution \\
\hline 1 & Speaker fast speech & $\begin{array}{l}\text { - being well-experienced } \\
\text { - improving listening skills } \\
\text { - knowing the topic beforehand } \\
\text { - listening actively }\end{array}$ \\
\hline 2 & Problems of sound system & - ensuring technical available of equipment \\
\hline 3 & Inactive listening & $\begin{array}{l}\text { - improving listening skills \& } \\
\text { - listening actively }\end{array}$ \\
\hline 4 & Lack of knowledge about topic events & - knowing the topic beforehand \\
\hline 5 & Lack of experience & - being well-experienced \\
\hline 6 & Long boring sentences & $\begin{array}{l}\text { - being visibly faced to the event relevant } \\
\text { - going beyond invisible meaning to the } \\
\text { intended one. }\end{array}$ \\
\hline 7 & Inaccurate pronunciation & - being acquainted with different dialects \\
\hline 8 & Ill-formed sentences & $\begin{array}{l}\text { - managing ill-formed sentences } \\
\text { - going beyond invisible meaning to the } \\
\text { intended one. }\end{array}$ \\
\hline 9 & Ambiguous speech & $\begin{array}{l}\text { - going beyond invisible meaning to the } \\
\text { intended one. }\end{array}$ \\
\hline 10 & Misuse of terminological expressions & - finding suitable terminologies \\
\hline 11 & ESP terminologies & - having a rich knowledge about ESP \\
\hline 12 & Audience interruption within interpretation & $\begin{array}{l}\text { - securing suitability of place and time } \\
\text { - arranging and setting levels of standard } \\
\text { and non-standard SI }\end{array}$ \\
\hline 13 & Lack of international terms & $\begin{array}{l}\text { - finding suitable terminologies } \\
\text { - having background knowledge about } \\
\text { idioms in general }\end{array}$ \\
\hline 14 & Lack of endurance & - being well-experienced \& being enduring \\
\hline 15 & Shortage of time & - being well-experienced \\
\hline
\end{tabular}




\begin{tabular}{|c|c|c|}
\hline & & $\begin{array}{l}\text { - improving listening skills } \\
\text { - knowing the topic beforehand } \\
\text { - listening actively }\end{array}$ \\
\hline 16 & Newly-coined idiomatic expressions & $\begin{array}{l}\text { - having background knowledge about } \\
\text { idioms in general }\end{array}$ \\
\hline 17 & Inability to team working & - being cooperative with his/her team \\
\hline 18 & The use of lexical items out of place & - finding suitable terminologies \\
\hline 19 & Cultural diversity & - accompanying bilingualism by biculturalism \\
\hline 20 & $\begin{array}{l}\text { Unsuitable atmosphere of place and time for } \\
\text { interpretation }\end{array}$ & $\begin{array}{l}\text { - securing suitability of place and time } \\
\text { - arranging and setting levels of standard and } \\
\text { non-standard SI }\end{array}$ \\
\hline 21 & Insufficient thematic knowledge & $\begin{array}{l}\text { - knowing the topic beforehand } \\
\text { - talking to the speaker before the event }\end{array}$ \\
\hline 22 & Homophonic words & $\begin{array}{l}\text { - knowing the topic beforehand } \\
\text { - listening actively }\end{array}$ \\
\hline 23 & Unforeseen terms & $\begin{array}{l}\text { - knowing the topic beforehand } \\
\text { - talking to the speaker before the event } \\
\text { - finding suitable terminologies } \\
\text { - going beyond invisible meaning to the } \\
\text { intended one. }\end{array}$ \\
\hline 24 & Variability of religious concepts & $\begin{array}{l}\text { - accompanying bilingualis } m \text { by biculturalism } \\
\text { - bridging the gap between religious } \\
\text { Differences }\end{array}$ \\
\hline 25 & Word order differences between SL and TL & $\begin{array}{l}\text { - considering structural differences between } \\
\text { languages } \\
\text { - being visibly faced to the event relevant }\end{array}$ \\
\hline 26 & Embarrassing situations & $\begin{array}{l}\text { - accompanying bilingualism by biculturalism } \\
\text { - being acquainted with different dialects } \\
\text { - being visibly faced to the event relevant } \\
\text { - going beyond invisible meaning to the } \\
\text { intended one } \\
\text { - being poised \& enduring }\end{array}$ \\
\hline 27 & Unpleasant voice & $\begin{array}{l}\text { - coping up with unpleasant voice } \\
\text { - being poised \& enduring }\end{array}$ \\
\hline 28 & All difficulties & - doing research \\
\hline
\end{tabular}




\section{Appendices}

\section{Appendix (A) \\ Difficulties of SI of the Focus Group}

\begin{tabular}{|c|c|c|c|c|c|c|c|c|c|c|c|c|c|c|}
\hline \multirow{2}{*}{ No. } & \multirow{2}{*}{ Difficulties } & \multicolumn{13}{|c|}{ Interpreters } \\
\hline & & $\mathbf{1}$ & 2 & 3 & 4 & $\mathbf{5}$ & 6 & 7 & 8 & 9 & $\mathbf{1 0}$ & 11 & 12 & 13 \\
\hline $\mathbf{1}$ & Syllabus Lacking of SI & & & & & & & & $\sqrt{ }$ & & & & & \\
\hline 2 & $\begin{array}{l}\text { Difference of Habits, Cultures, } \\
\text { Attitudes }\end{array}$ & $\sqrt{ }$ & $\sqrt{ }$ & $\sqrt{ }$ & & $\sqrt{ }$ & 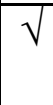 & $\sqrt{ }$ & & $\sqrt{ }$ & $\sqrt{ }$ & $\sqrt{ }$ & & $\sqrt{ }$ \\
\hline 3 & Quickness & & & & $\sqrt{ }$ & & & $\sqrt{ }$ & & & $\sqrt{ }$ & & & \\
\hline 4 & Dialect Ambiguity & & $\sqrt{ }$ & $\sqrt{ }$ & & $\sqrt{ }$ & & $\sqrt{ }$ & & & $\sqrt{ }$ & $\sqrt{ }$ & & \\
\hline 5 & Time Shortages & & & $\sqrt{ }$ & & & $\sqrt{ }$ & $\sqrt{ }$ & & & & & & \\
\hline 6 & Phonological Difficulties & & & & & & & $\sqrt{ }$ & & $\sqrt{ }$ & $\sqrt{ }$ & $\sqrt{ }$ & & \\
\hline 7 & $\begin{array}{l}\text { Differences of Structures between } \\
\text { Languages }\end{array}$ & & $\sqrt{ }$ & $\sqrt{ }$ & $\sqrt{ }$ & & 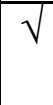 & V & & & $\sqrt{ }$ & & & $\sqrt{ }$ \\
\hline 8 & $\begin{array}{l}\text { Audience s' Questions in time of } \\
\text { Interpreting }\end{array}$ & & $\sqrt{ }$ & & & & & & & & & & & \\
\hline 9 & Lack of International Terms & & & $\sqrt{ }$ & & & & & & & & & & \\
\hline 10 & Non-Professional Speaker & & & $\sqrt{ }$ & & & $\sqrt{ }$ & & & & & & & \\
\hline 11 & Missing Words & & & & & $\sqrt{ }$ & & & $\sqrt{1}$ & & & & & \\
\hline 12 & Lack of Experience & & & & & & & & & & $\sqrt{ }$ & & $\sqrt{ }$ & \\
\hline 13 & Sound System Problems & & & & & & & & $\sqrt{ }$ & & & & & \\
\hline 14 & Lacking Equipment of SI & & & & $\sqrt{ }$ & & & & & & & & & \\
\hline 15 & Lacking Professional Training & & & & & & $\sqrt{ }$ & & $\sqrt{ }$ & & & & & \\
\hline 16 & Insufficient Thematic knowledge & & & & $\sqrt{ }$ & & & & & & $\sqrt{ }$ & & & \\
\hline 17 & Divine Question like that in Qur'an & & & & & & $\sqrt{ }$ & & & & & & & \\
\hline 18 & Idiomatic Expression & & & $\sqrt{ }$ & $\sqrt{ }$ & & & & & & & & & \\
\hline 19 & New Idioms and Expressions & & & & & & & & $\sqrt{ }$ & & & $\sqrt{ }$ & & \\
\hline 20 & Suitability of the Setting & & & & & $\sqrt{ }$ & & $\sqrt{ }$ & & & & & & \\
\hline 21 & Homophonic words & & & $\sqrt{ }$ & & $\sqrt{ }$ & $\sqrt{ }$ & & $\sqrt{ }$ & $\sqrt{ }$ & & & & \\
\hline 22 & Long speech & & & & & & & & & $\sqrt{ }$ & & & & \\
\hline
\end{tabular}




\section{Appendix (B)}

Suggested Solutions for Difficulties of SI of the Focus Group

\begin{tabular}{|c|c|c|c|c|c|c|c|c|c|c|c|c|c|c|}
\hline \multirow{2}{*}{ No. } & \multirow{2}{*}{ Suggested Solutions } & \multicolumn{13}{|c|}{ Interpreters } \\
\hline & & $\mathbf{1}$ & 2 & 3 & 4 & 5 & 6 & 7 & 8 & 9 & $\mathbf{1 0}$ & 11 & 12 & 13 \\
\hline 1 & Finding suitable terminologies & & $\sqrt{ }$ & $\sqrt{ }$ & $\sqrt{ }$ & & $\sqrt{ }$ & & $\sqrt{ }$ & & $\sqrt{ }$ & $\sqrt{ }$ & $\sqrt{ }$ & \\
\hline 2 & Doing research & & & & & & & & & & $\sqrt{ }$ & & & \\
\hline 3 & $\begin{array}{l}\text { Ensuring technical equipment are } \\
\text { available }\end{array}$ & & & & $\sqrt{ }$ & & & $\sqrt{ }$ & & & & & & \\
\hline 4 & Knowing the topic beforehand & & $\sqrt{ }$ & $\sqrt{ }$ & & $\sqrt{ }$ & & $\sqrt{ }$ & & & & & & \\
\hline 5 & $\begin{array}{l}\text { Talking with the delicate before the } \\
\text { event }\end{array}$ & & & & & & & $\sqrt{ }$ & & & & & & \\
\hline 6 & $\begin{array}{l}\text { Arranging and Sitting Levels of SI } \\
\text { Horizontally and Vertically }\end{array}$ & & & & & & & & & & & $\sqrt{ }$ & & \\
\hline 7 & Fluently Speaker & & $\sqrt{ }$ & $\sqrt{ }$ & & & & & & & & & & \\
\hline 8 & Patience and Resilience & & $\sqrt{ }$ & & & & & & $\sqrt{ }$ & $\sqrt{ }$ & & & & \\
\hline 9 & Improving listening Skills & & & $\sqrt{ }$ & & & & & & & & & & \\
\hline 10 & Idioms & & & & & & $\sqrt{ }$ & & & & & & & \\
\hline 11 & $\begin{array}{l}\text { Familiarity with Different } \\
\text { Ideological and Cultures }\end{array}$ & $\sqrt{ }$ & $\sqrt{ }$ & $\sqrt{ }$ & & $\sqrt{ }$ & & & $\sqrt{ }$ & & & & & \\
\hline 12 & Paraphrasing & & & & $\sqrt{ }$ & $\sqrt{ }$ & $\sqrt{ }$ & & & & $\sqrt{ }$ & & $\sqrt{ }$ & \\
\hline 13 & Improving Memory skills & & & & & & & & $\sqrt{ }$ & & $\sqrt{1}$ & $\sqrt{ }$ & $\sqrt{ }$ & $\sqrt{ }$ \\
\hline 14 & Focusing on the Idea & & & & $\sqrt{ }$ & & $\sqrt{ }$ & $\sqrt{ }$ & & & & & $\sqrt{ }$ & \\
\hline
\end{tabular}

Appendix (C)

Difficulties of SI of the Questionnaire

\begin{tabular}{|c|c|c|c|c|c|c|}
\hline No. & Items & 党 & 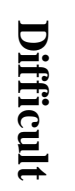 & 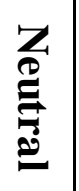 & 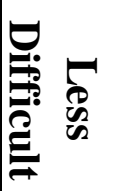 & 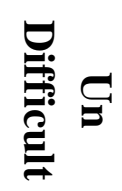 \\
\hline 1 & Unpleasant voice & & & & & \\
\hline 2 & Inaccurate pronunciation & & & & & \\
\hline 3 & Speakers' fast speech & & & & & \\
\hline 4 & Homophonic words & & & & & \\
\hline 5 & Word order differences between the SL and TL & & & & & \\
\hline
\end{tabular}




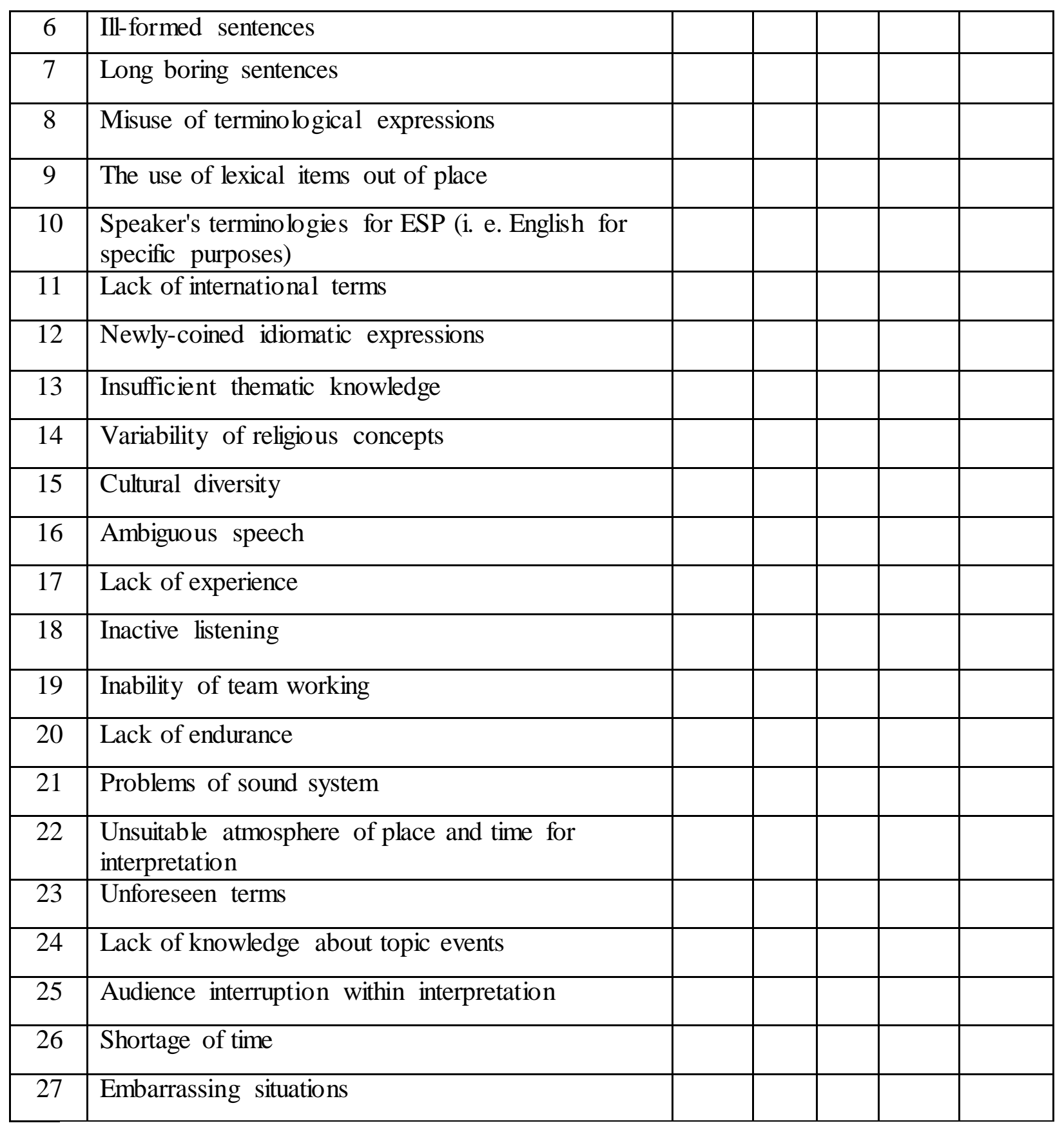




\section{Appendix (D)}

Suggested Solutions for Difficulties of SI of the Questionnaire

\begin{tabular}{|c|c|c|c|c|c|c|}
\hline No. & Items & 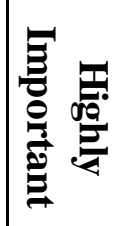 & 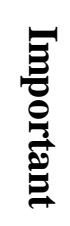 & 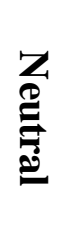 & 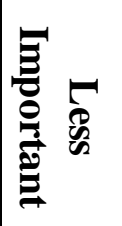 & 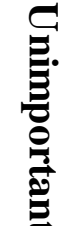 \\
\hline 1 & Being acquainted with different dialects & & & & & \\
\hline 2 & Coping up with unpleasant tone & & & & & \\
\hline 3 & $\begin{array}{l}\text { Considering structural differences between } \\
\text { languages }\end{array}$ & & & & & \\
\hline 4 & Managing ill-formed sentences & & & & & \\
\hline 5 & Finding suitable terminologies & & & & & \\
\hline 6 & Having a rich knowledge about ESP & & & & & \\
\hline 7 & $\begin{array}{l}\text { Having background knowledge about idioms in } \\
\text { general }\end{array}$ & & & & & \\
\hline 8 & $\begin{array}{l}\text { Going beyond the invisible meaning to the intended } \\
\text { one }\end{array}$ & & & & & \\
\hline 9 & Bridging the gap between the religious differences & & & & & \\
\hline 10 & Accompanying bilingualism by biculturalism & & & & & \\
\hline 11 & Improving listening skills & & & & & \\
\hline 12 & Talking to the speaker before the event & & & & & \\
\hline 13 & Improving memorization skills & & & & & \\
\hline 14 & Being well-experienced & & & & & \\
\hline 15 & Listening actively & & & & & \\
\hline 16 & Working in a team & & & & & \\
\hline 17 & Endurance & & & & & \\
\hline 18 & Doing research & & & & & \\
\hline 19 & Ensuring technical equipment are available & & & & & \\
\hline 20 & \begin{tabular}{|l} 
Securing suitability of place and time \\
\end{tabular} & & & & & \\
\hline 21 & Being visibly faced to the event relevant & & & & & \\
\hline 22 & Knowing the topic beforehand to preparing & & & & & \\
\hline 23 & $\begin{array}{l}\text { Arranging and setting levels of standard and non- } \\
\text { standard SI }\end{array}$ & & & & & \\
\hline
\end{tabular}


Journal of the University of Garmian 6 (1), 2019 